\title{
Processing and release of human proinsulin-cleavage products into culture media by different engineered non-endocrine cells: a specific assessment by capillary electrophoresis
}

\author{
C Arcelloni ${ }^{1}$, L Falqui ${ }^{2,3}$, S Martinenghi ${ }^{3}$, A Stabilini ${ }^{2}$, \\ A E Pontiroli ${ }^{4}$ and $\mathbf{R}$ Paroni ${ }^{1}$ \\ ${ }^{1}$ Laboratory of Separative Techniques, Department of Laboratory Medicine, Scientific Institute H S Raffaele and School of Medicine, Milan, Italy \\ ${ }^{2}$ Telethon Institute for Gene Therapy, Department of Biotechnology (DIBIT), Scientific Institute H S Raffaele and School of Medicine, Milan, Italy \\ ${ }^{3}$ Department of Internal Medicine, Scientific Institute H S Raffaele and School of Medicine, Milan, Italy \\ ${ }^{4}$ Department of Science and Biomedical Technology, University of Milan, Italy \\ (Requests for offprints should be addressed to C Arcelloni, Via Olgettina,60, Milan 20132, Italy; Email: arcelloni.cinzia@hsr.it)
}

\begin{abstract}
The aim of this study was to compare the metabolic pathway to mature insulin through the intermediate forms (32-33 split, 65-66 split, des31,32 and des64,65) in human or murine cells engineered for the release of wild-type human proinsulin and in a genetically mutated one, in the search for a new approach for an insulindependent diabetes mellitus cure by gene therapy.

Primary human fibroblasts, myoblasts and stabilized cell lines (HepG2 and NIH3T3) were transduced either with a retroviral vector coding for wild-type proinsulin or for a genetically mutated one, carrying cleavage sites sensitive to furin. The pattern of all the proinsulin cleavage products released into the cell culture supernatants was analyzed by capillary electrophoresis.

All the cells transduced with the wild-type gene released intact proinsulin. HepG2 released a considerable
\end{abstract}

amount of 65-66 split and des64,65, while primary myoblasts released all the intermediate forms and a limited amount of mature insulin. All the cells transduced with a furin-sensitive proinsulin gene released a higher amount of mature insulin (23-59\% conversion yield) than the cells expressing wild-type proinsulin, whereas the total insulin was nearly constant. Only primary cells released all the cleavage products.

Screening a wide variety of non-endocrine cells has revealed a large difference in the processing and release of immature and mature insulin forms, pointing to human hepatic cells as the most efficacious. Capillary electrophoresis provided on-line and in a single run a complete overview of the proinsulin metabolic pathway in different cells.

Journal of Endocrinology (2000) 166, 437-445

\section{Introduction}

In the search for a gene therapy-based cure for diabetes (Kolodka et al. 1995, Levine 1997), many different nonendocrine cells have been genetically modified by introduction of the human pre-proinsulin gene (HPI), thus obtaining synthesis of the prohormone (Groskreutz et al. 1994). In non-endocrine cells, furin, a Golgi-anchored enzyme (Groskreutz et al. 1994, Vollenweider et al. 1995) whose concentration is cell line specific, exerts a proteolytic activity like PC2 and PC3 (endocrine cell-restricted endoproteases) recognizing a cleavage site composed of the tetra-basic amino acid sequence $\mathrm{Arg}^{-4}-\mathrm{X}^{-3}$-Lys $/ \mathrm{Arg}^{-2}{ }_{-}$ $\mathrm{Arg}^{-1}-\mathrm{X}^{+1}$. As a following step, the human proinsulin (hPI) cDNA was modified, inserting the furin-cleavable motifs at the B chain/C-peptide and C-peptide/A chain junctions (Falqui et al. 1999). The furin-cleavable hPI gene (FurHPI) permanently expressed a double-mutated protein more easily cleavable by furin into mature insulin at a conversion rate which correlates well with the furin expression (Yanagita et al. 1993). In the secretory granules of pancreatic beta cells hPI is processed to mature human insulin (hI) through the formation of four intermediate forms (des31,32; 32-33 split; des64,65 and 65-66 split) (Fig. 1) (Rhodes \& Halban 1987, Vollenweider et al. 1992, Halban 1994, Hutton 1994, Kahn \& Halban 1997) whose accumulation can vary in relation to pathological conditions (Sizonenko et al. 1993, Ward et al. 1987, Yoshioka et al. 1988, Mykkanen et al. 1997).

In order to verify the proinsulin metabolism in nonendocrine cells transduced both with the wild-type human proinsulin gene (HPI) and with modified HPI, a specific method able to quantify all the conversion products is necessary. RIA gives the 'total immunoreactive insulin' 




Figure 1 Processing from $\mathrm{hPl}$ to $\mathrm{hl}$ via the intermediate forms. The amino acids at the cleavage sites 31, 32 and 64,65 are indicated in the one-letter code. R: Arg, K: Lys.

(IRI) because of its cross-reaction with the proinsulin-like molecules, hI and C-peptide. This property leads to overestimation of the mature insulin concentration, particularly when proinsulin and intermediates are increased (Temple et al. 1989, 1990, Crowther \& Gray 1996). IRMA- (Mohamed-Ali et al. 1996) and ELISA-based assays (Tao \& Kennedy 1997) can only detect analytes for which the specific antibodies have been raised, so more versatile analytical procedures based on HPLC (Nagi et al. 1990, Vollenweider et al. 1992, Ostrega et al. 1995), mass-spectrometry (MS) (Stocklin et al. 1997) or capillary electrophoresis (CE) (Tao \& Kennedy 1997, Tao et al. 1998) have been developed.
A new, interesting tool for protein quantification is represented by CE (Nielsen et al. 1989, Chen \& Sternberg 1994, Nashabeh et al. 1994), which has been shown to separate complex protein mixtures with remarkable resolving power by exploiting the differences in charge/ mass ratio of the analytes (Oda et al. 1997, Bergmann et al. 1998). Its advantages can be summarized as: on-line detection of different kinds of molecules in the same run, low reagent volume consumption, low sample requirements, and the possibility of automation.

The aim of this study was to make a comparison of the hPI metabolism in different non-endocrine stabilized or primary cell lines transfected both with the wild-type and 
with the modified gene constructs. To reach this goal hPI, $\mathrm{hI}$ and the split and des intermediate forms released into the cell supernatants were purified by solid phase extraction and directly quantified by capillary zone electrophoresis (CZE) coupled with UV absorbance (Arcelloni et al. 1998).

\section{Materials and Methods}

\section{Standard proteins}

hI was purchased from Boehringer (Mannheim, Germany) and the lyophilized powder reconstituted with bi-distilled water to a final concentration of $1.6 \mathrm{mmol} / \mathrm{l}$. hPI, des31,32, des64,65, 32-33 split and 65-66 split were kindly donated by Eli Lilly and Company (Indianapolis, IN, USA) and reconstituted with water to a final concentration of $20 \mu \mathrm{mol} / \mathrm{l}$. Aliquots were stored at $-20{ }^{\circ} \mathrm{C}$.

\section{Retroviral vector and cell transduction}

The insertion of the EcoR1/Hga1343 bp fragment of the wild-type hPI into the EcoR1/Hpa1 sites of retroviral vector L-X-SFCM, derived from the Moloney murine leukemia virus backbone, was described previously (Falqui et al. 1999). For cell marking and selection, the L-XSFCM vector coding for the truncated human low-affinity nerve growth factor receptor ( $\triangle \mathrm{LNGFR})$, was employed (Mavilio et al. 1994). Subsequently, two mutations were introduced by PCR technique into the wild hPI cDNA, to obtain the permanent synthesis of a proinsulin molecule with modified cleavage sites (Falqui et al. 1999). The modified hPI cDNA (FurHPI) was then inserted into the LX-SFCM retroviral vector. The generation of infective supernatants with high titers of viral particles was obtained in packaging cells, as previously described (Mavilio et al. 1994, Falqui et al. 1999). Infective supernatants were harvested from confluent packaging cells and overlaid for $24 \mathrm{~h}$ onto target cells in the presence of polybrene $(8 \mu \mathrm{g} / \mathrm{ml})$. After 1 week, the percentage of retrovirally transduced cells was evaluated by flow cytometry for de novo surface expression of $\triangle \mathrm{LNGFR}$.

\section{Cell culture and media collections}

Primary human fibroblasts (PHF) and HepG2 were cultured in Dulbecco's modified Eagle's medium (DMEM) (GIBCO Life Technologies, Paisley, Scotland) supplemented with 10\% (v/v) fetal calf serum (FCS) (Sigma, St Louis, MO, USA), whereas murine fibroblasts (NIH3T3) were cultured in DMEM supplemented with $10 \%(\mathrm{v} / \mathrm{v})$ newborn calf serum and primary rat hepatocytes $(\mathrm{PRH})$ in Medium 199 (GIBCO) supplemented with growth factors. Primary human myoblasts (PHM) were cultured in RPMI medium containing 20\% FCS. For CZE analysis, culture media were harvested after 24 or $48 \mathrm{~h}$ of incubation. Cells were counted and hPI, hI and intermediates accumulation in culture media was expressed as pmol/24 h per $10^{6} \Delta$ LNGFR-positive cells.

$C Z E$

All reagents were of analytical grade. Diethylenetriamine (DETA), N-[tris(hydroxymethyl)methyl]-3-aminopropanesulfonic acid (TAPS), trifluoroacetic acid and acetonitrile were from Fluka (Buchs, Switzerland). The analyses were carried out with slight modifications of the previously published procedure (Arcelloni et al. 1998) to allow resolution of all the proinsulin cleavage products. A P/ACE 5010 equipped with UV detector and computer controlled (Beckman, Palo Alto, CA, USA) was used. All the proteins were separated in an uncoated fused silica capillary $(50 \mu \mathrm{m}$ i.d. $\times 27 \mathrm{~cm}$ total, $20 \mathrm{~cm}$ to the detector) eluted with a running buffer composed of TAPS $100 \mathrm{mmol} / \mathrm{l}, \mathrm{pH} 11 \cdot 5$, DETA $17 \cdot 8 \mathrm{mmol} / \mathrm{l}$ and methanol $(45: 45: 10 \mathrm{v} / \mathrm{v} / \mathrm{v})$, at a constant voltage of $+9 \mathrm{kV}$ (about $18 \mu \mathrm{A})$. The detector was set at $200 \mathrm{~nm}$ and the capillary thermostated at $20^{\circ} \mathrm{C}$.

\section{Purification procedure}

Cell supernatants $(20-30 \mathrm{ml})$ were purified as described (Arcelloni et al. 1998). Briefly, after a solid-phase extraction with Sep-Pak Vac $6 \mathrm{ml}, \mathrm{C}_{18} 500 \mathrm{mg}$ cartridges (Waters, Milford, MA, USA), the fraction containing the proteins of interest was concentrated under vacuum and ultrafiltered (Centricon-50, $50000 M_{\mathrm{r}}$ cut-off; Amicon Division, Beverly, MA, USA). Aliquots of the ultrafiltrates were injected (5-10 s, corresponding to $9 \cdot 8-19 \cdot 5 \mathrm{nl}$ ) at pressure mode $3 \cdot 4 \times 10^{-3} \mathrm{MPa}$.

\section{hI and hPI routine assay}

RIA Determination of IRI was carried out by RIA (Insulin RIA Kit; Incstar Corporation, Stillwater, MN, USA). The standard curve concentration ranged from 0 to $600 \mathrm{pmol} / 1 .{ }^{125} \mathrm{I}$-insulin, antibody and anti-insulin serum were incubated overnight at $4{ }^{\circ} \mathrm{C}$. Precipitating complex was added, vortexed, centrifuged and the supernatant discarded. Radioiodine in the precipitates was counted for $60 \mathrm{~s}$ using a gamma scintillation counter. The polyclonal antibodies used cross-react 100\% with bovine and porcine insulin and 30-80\% with proinsulin-like molecules.

hI IRMA The determination of mature insulin was done with a BI-INSULIN IRMA kit (Sanofi-Diagnostic Pasteur, Paris, France), based on a monoclonal antibody. The analytical range was $1 \cdot 4-3000 \mathrm{pmol} / 1$ and the 


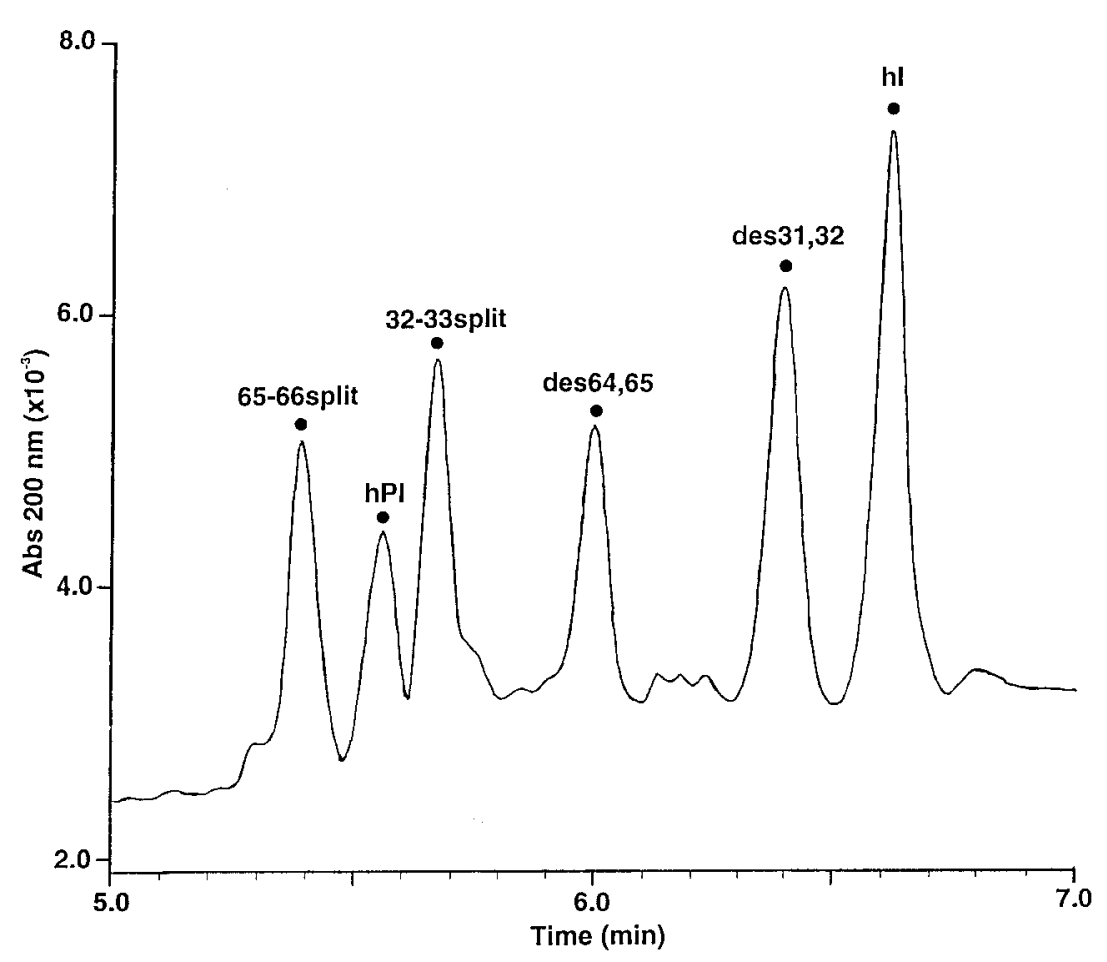

Figure 2 Representative electropherogram of hl, hPl and hPI conversion products (about $4 \mu \mathrm{M}$ each protein) injected for $5 \mathrm{~s}$ (about $50 \mathrm{fmol}$ of each protein) in an uncoated fused silica capillary under the electrophoretic conditions described in Materials and Methods.

cross-reactivity was $100 \%$ with porcine and bovine insulin and 65-66 split or des64,65 proinsulin, while $<0 \cdot 0001 \%$ with hPI and 32-33 split and des31,32.

ELISA Two non-isotopic microplate assays (Dako, Glostrup, Denmark) for total hPI and intact hPI (IhPI) proinsulin were used. The first assay detects unprocessed hPI and cross-reacts (65-99\%) with all intermediate forms of hPI (32-33 split, des31,32; 65-66 split and des64,65) while the IhPI assay detects the unprocessed molecule along with 65-66 split and des64,65. Antibodies used in the kits give a cross-reactivity of $0 \cdot 1 \%$ with insulin and C-peptide. The standard analytical range was $0-100 \mathrm{pmol} / 1$ and the detection limit $<0 \cdot 2 \mathrm{pmol} / 1$ for both (as provided by the manufacturer).

\section{Results}

Validation of CZE analysis showed a calculated recovery rate for each protein from solid-phase extraction of $85 \pm 14 \%$ (s.D.) and a sensitivity limit of the CZE analysis of $2 \mathrm{fmol}$ injected, corresponding to $0.5 \mathrm{nmol} / 1$ in the supernatant. The response was linear in the $0 \cdot 1-10 \mu \mathrm{mol} / 1$ range corresponding to $2-200 \mathrm{nmol} / 1$ in the supernatants. With respect to the already published method (Arcelloni et al. 1998), the separation has now been optimized to include also 32-33 split. In Fig. 2 is reported the electrophoretic separation of the six standard proteins. Figure 3 shows the electropherograms obtained by analysis of the supernatants from non-transfected PHM cells, PHM-HPI and PHM-FurHPI cells. The abundant peak at $6.4 \mathrm{~min}$ (just before hI) is unrelated to cell metabolism, being present in all the fresh culture media employed for cells growth (data not shown). By adding increasing amounts of standard hI to wild-type supernatant, however, its resolution from the big peak migrating just before was never hindered. The major peaks at $7 \cdot 4,7 \cdot 8$ and $10 \cdot 0 \mathrm{~min}$, together with numerous other minor peaks were present in both transfected cells but not in the non-transfected lines. Although their identification is not available yet, they are probably related to proinsulin production by these cells and can be also used for monitoring cell transfection.

The identification of the (pro)insulin-related proteins within the rather complex electrophoretic profiles was accomplished by an extensive post-analytical review with the System Gold software (Beckman version 8.1). First a comparison with a non-transfected supernatant spiked with the pure standard and extracted as the unknown samples was done (external calibration). The good reproducibility of the migration time (Mt) and the presence of 


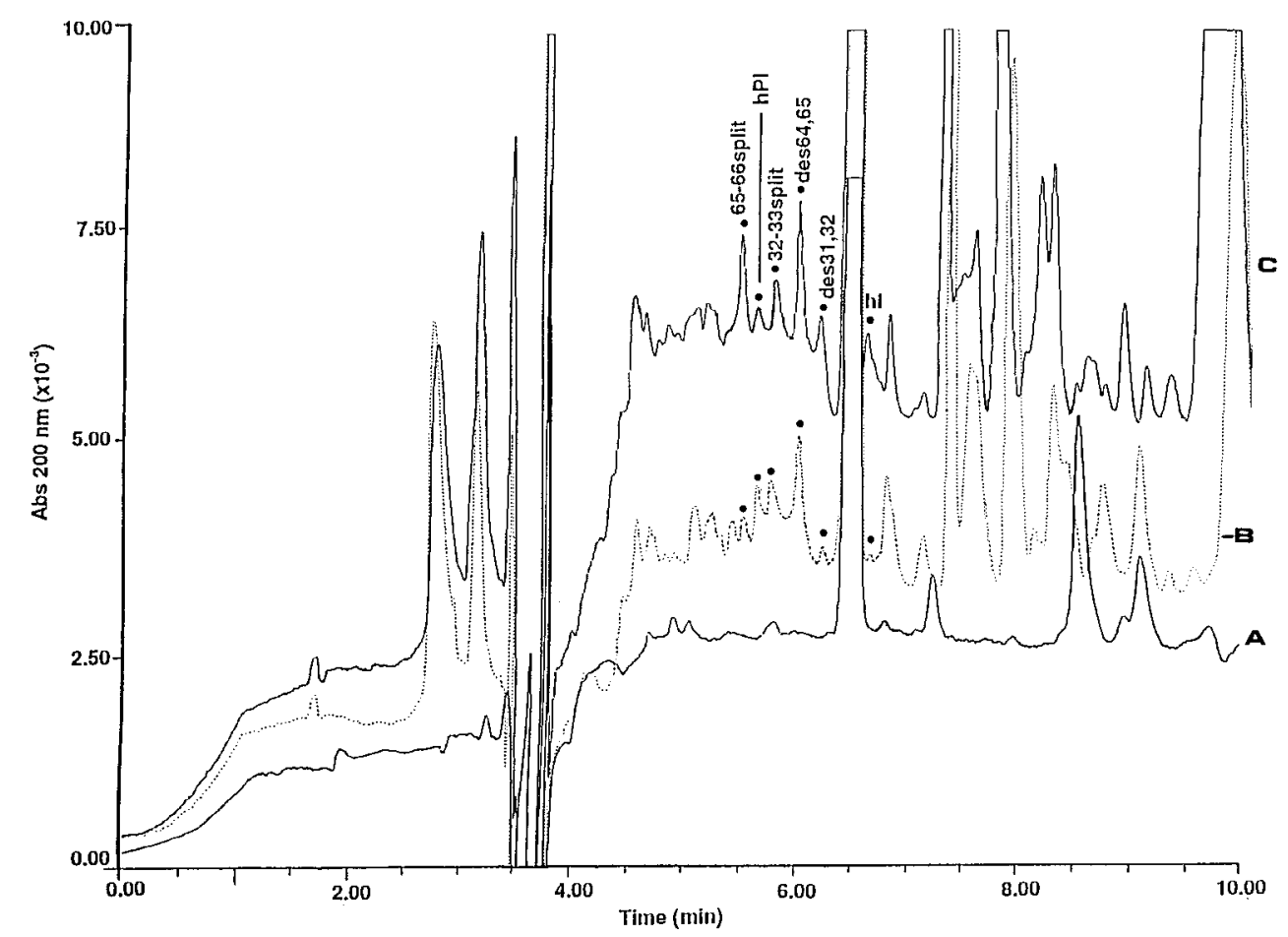

Figure 3 Representative electropherograms of non-transduced PHM (A), PHM-HPI (B) and PHM-FurHPI (C) supernatants. Samples were injected for $10 \mathrm{~s}$ and the peaks of hPl, 32-33 split, des31,32, 65-66 split, des64,65 and hl were identified by enrichment of aliquots of the samples with the pure standard proteins. The peak having Mt $6.4 \mathrm{~min}$ was present in all the profiles (A, B, C) and is related to a culture medium component. The other major peaks (Mt 7·4, $7 \cdot 8$ and $10 \mathrm{~min}$ ) found only in both the transfected cells and not in the wild-type ones, may be related to cell transfection and hPI production.

some important peaks taken as 'references' for peak assignment ensured the accuracy of the procedure. The identification of the separated components, however, was always confirmed by co-injection of the samples with one pure standard at a time. The increase of only one peak with respect to the surrounding ones was always well evidenced and confirmed the previous assignment. No peaks at the Mt of the proteins under investigation were found in the CZE profile of the non-transfected cells.

\section{(Pro)insulin metabolism in transduced cell supernatants}

hPI was produced by all the HPI cell lines investigated, at a rate ranging from $0 \cdot 6 \pm 0 \cdot 2$ (S.D) to $1.9 \pm 1.2 \mathrm{pmol} / 24 \mathrm{~h}$ per $10^{6}$ cells, while mature insulin (as expected) was never identified in these cells, except for a small amount (less than $1.0 \%$ of the total (pro)insulin-related proteins) in PHM-HPI cells (B in Fig. 3; Table 1). Looking at the sum of all the (pro)insulin-related proteins, PHM-HPI displayed the highest production efficiency. The metabolism of HepG2 cells seems to be more prone toward maturation products like 65-66 split and des64,65 (35 and 46\% respectively) while in PHF culture media the major components were intact hPI and des31,32 (50 and 35\% respectively) and NIH3T3 released a high amount $(68 \%$ of all the (pro)insulin-related proteins) of 32-33 split. When cells were genetically modified to express the FurHPI, mature hI was found to accumulate in the culture media of all the FurHPI cell lines at a rate ranging from $0 \cdot 6 \pm 0 \cdot 1 \mathrm{pmol} / 24 \mathrm{~h}$ per $10^{6}$ cells in PRH and NIH3T3 cells to $2 \cdot 4 \pm 0 \cdot 3 \mathrm{pmol} / 24 \mathrm{~h}$ per $10^{6}$ cells in the HepG2 (Table 1). The conversion of intermediates to hI was decreased in the order HepG2 $>$ NIH3T3 $>$ PRH $>$ PHF $>$ PHM (59, 46, 32, 26 and 23\% respectively). PHF and PHM showed in the media the presence of all the intermediate forms of hPI to hI maturation (C in Fig. 3), while in HepG2 cells only accumulation of des64,65 (34\%) was found. Conversely, PRH released into the supernatant only a large amount of des31,32 (68\%) in addition to mature hI (32\%). Traces of unprocessed hPI were observed in all cells except PRH (Table 1).

\section{Immunological assays}

In non-transduced cells, RIA and hI IRMA values were always under the detection limit (data not shown). Comparison of results obtained by CZE with RIA and hI IRMA determinations are reported in Table 2. The sum of 
Table $1 \mathrm{CE}$ analysis of supernatants of retrovirally transduced cells. Values are means \pm S.D. pmol/24 h per $10^{6}$ cells of three different cell incubations. Each purified sample was injected into the CZE five times

\begin{tabular}{|c|c|c|c|c|c|c|c|}
\hline & hPI & 32-33split & $\operatorname{des} 31,32$ & 65-66split & $\operatorname{des} 64,65$ & hl & Total \\
\hline PHM & $1 \cdot 9 \pm 1 \cdot 2$ & $0 \cdot 6 \pm 0 \cdot 1$ & $1 \cdot 1 \pm 0 \cdot 8$ & $0 \cdot 5 \pm 0 \cdot 3$ & $1 \cdot 6 \pm 0 \cdot 1$ & $0 \cdot 05$ & $5 \cdot 8 \pm 1 \cdot 0$ \\
\hline PHF & $1 \cdot 8 \pm 0 \cdot 2$ & $0 \cdot 2 \pm 0 \cdot 1$ & $1 \cdot 6 \pm 0 \cdot 6$ & n.d. & n.d. & n.d. & $3 \cdot 6 \pm 1 \cdot 2$ \\
\hline HepG2 & $0 \cdot 6 \pm 0 \cdot 3$ & n.d. & n.d. & $1 \cdot 3 \pm 0 \cdot 1$ & $1 \cdot 7 \pm 0 \cdot 6$ & n.d. & $3 \cdot 7 \pm 0 \cdot 9$ \\
\hline \multicolumn{8}{|c|}{ FurHPI cells } \\
\hline PHM & $1 \cdot 3 \pm 0 \cdot 1$ & $0 \cdot 6 \pm 0 \cdot 1$ & $1 \cdot 9 \pm 0 \cdot 1$ & $0 \cdot 6 \pm 0 \cdot 4$ & $1 \cdot 1 \pm 0 \cdot 2$ & $1.6 \pm 0 \cdot 5$ & $6 \cdot 8 \pm 1 \cdot 0$ \\
\hline NIH3T3 & $0 \cdot 3 \pm 0 \cdot 1$ & $0 \cdot 2 \pm 0 \cdot 1$ & $0 \cdot 2 \pm 0 \cdot 1$ & n.d. & n.d. & $0 \cdot 6 \pm 0 \cdot 1$ & $1 \cdot 3 \pm 0 \cdot 2$ \\
\hline HepG2 & $0 \cdot 2 \pm 0 \cdot 02$ & n.d. & n.d. & n.d. & $1 \cdot 4 \pm 0 \cdot 3$ & $2 \cdot 4 \pm 0 \cdot 3$ & $4 \cdot 1 \pm 1 \cdot 3$ \\
\hline
\end{tabular}

n.d. under the detection limit.

all (pro)insulin-related proteins calculated by CZE was in good agreement with the RIA quantification, while IRMA value appeared overestimated with respect to the mature hI quantification by CZE.

Some of the samples were tested also with two ELISA kits developed for total and intact hPI determination on human plasma. The tests carried out directly on the cell culture media yielded an hPI overestimation of 130-600\% (data not shown). This was corrected neither by 1:8000 dilution with a human serum pool, nor by purification of the supernatant or by the procedure described for CZE.

\section{Discussion}

The gene therapy approach to insulin-dependent diabetes mellitus requires the development of a retroviral vectorbased system able to induce the permanent production, in a regulated way, of mature insulin in endocrine (Clark et al. 1997) or non-endocrine (Falqui et al. 1999) cell lines. To evaluate the metabolic activity of transfected cells, however, an accurate method able to detect the residual hPI, mature hI and all the other related cleavage products is necessary. The determination of hI and intact hPI (Deberg et al. 1998, Houssa et al. 1998) without interference from the intermediates is now possible thanks to the availability of RIA and ELISA tests for plasma or serum based on the use of specific monoclonal antibodies. However, the quantification of each single split- or des- form remains still laborious. Some groups successfully employ HPLC to separate hPI, hI and the intermediate forms and RIA to quantify the proteins in the collected fractions (Nagi et al. 1990, Vollenweider et al. 1992, Ostrega et al. 1995). Alternatively, cells are labeled with $\left[{ }^{3} \mathrm{H}\right]$ leucine, $\left[{ }^{35} \mathrm{~S}\right]$ cysteine or $\left[{ }^{35} \mathrm{~S}\right]$ methionine, immunoprecipitated with anti-insulin antibodies and the radioactivity associated with each peak evaluated directly on the collected

Table 2 Comparison between CZE, RIA and IRMA quantification of total (pro)insulin related-proteins and mature hl. Values are means \pm S.D. pmol/24 h $10^{6}$ cells of three determinations

\begin{tabular}{|c|c|c|c|c|}
\hline & \multicolumn{2}{|c|}{ Total (pro)insulin-related proteins } & \multicolumn{2}{|l|}{ Mature hl } \\
\hline & $\overline{\mathrm{RIA}}$ & CZE & IRMA & CZE \\
\hline \multicolumn{5}{|c|}{ HPI cells } \\
\hline PHM & $6 \cdot 0 \pm 1 \cdot 5$ & $5 \cdot 8 \pm 1 \cdot 0$ & $1 \cdot 3$ & $0 \cdot 05$ \\
\hline PHF & $2 \cdot 3 \pm 0 \cdot 7$ & $3 \cdot 6 \pm 1 \cdot 2$ & n.d. & n.d. \\
\hline NIH3T3 & $2 \cdot 2 \pm 1 \cdot 6$ & $1.9 \pm 0.9$ & n.d. & n.d. \\
\hline HepG2 & $3 \cdot 8 \pm 1 \cdot 3$ & $3 \cdot 7 \pm 1 \cdot 6$ & n.a. & n.d. \\
\hline \multicolumn{5}{|c|}{ FurHPI cells } \\
\hline PHM & $4 \cdot 1 \pm 1 \cdot 2$ & $6 \cdot 8 \pm 1 \cdot 0$ & $2 \cdot 3 \pm 0 \cdot 2$ & $1 \cdot 6 \pm 0 \cdot 5$ \\
\hline PHF & $5 \cdot 0 \pm 2 \cdot 3$ & $4 \cdot 6 \pm 1 \cdot 0$ & $3 \cdot 0 \pm 0 \cdot 7$ & $1 \cdot 2 \pm 0 \cdot 1$ \\
\hline $\mathrm{PRH}$ & $1 \cdot 3 \pm 0 \cdot 2$ & $1 \cdot 9 \pm 0 \cdot 7$ & $0 \cdot 8 \pm 0 \cdot 3$ & $0 \cdot 6 \pm 0 \cdot 1$ \\
\hline NIH3T3 & $1 \cdot 5 \pm 0 \cdot 2$ & $1 \cdot 3 \pm 0 \cdot 2$ & $1 \cdot 0 \pm 0 \cdot 3$ & $0 \cdot 6 \pm 0 \cdot 1$ \\
\hline HepG2 & $4 \cdot 5 \pm 1 \cdot 4$ & $4 \cdot 1 \pm 1 \cdot 3$ & $4 \cdot 2 \pm 0 \cdot 2$ & $2 \cdot 4 \pm 0 \cdot 3$ \\
\hline
\end{tabular}

n.d. under the detection limit.

n.a. quantification not available. 
fractions (Neerrman-Arbez et al. 1993, Sizonenko et al. 1993, Kaufmann et al. 1997). Although these remain the only methods providing the required sensitivity for the determination in plasma of all the proinsulin intermediates, the approach is based on two or more steps and on the use of labeled compounds. Recently, an isotope dilution MS (ID-MS) method was proposed for insulin analysis in human plasma (Stocklin et al. 1997) and affinity CE-based methods employing fluorescence detection were optimized to monitor insulin secretion from islets of Langerhans (Tao \& Kennedy 1997, Tao et al. 1998). However, both ID-MS and affinity CE methods are specific only for hI but not for the intermediate forms.

CZE has been successfully employed to detect the hPI to mature hI processing in the culture medium of engineered PHFs (Arcelloni et al. 1998, Falqui et al. 1999). In this paper the method has been improved to allow the direct quantification of hPI and of four intermediate forms, including the 32-33 split, which was previously lacking in our standard mixture. Quantification of single intermediates by RIA is not available, in fact, and only their sum can be evaluated as the RIA - IRMA difference. Cross-reactivity of 65-66 split and des64,65 in the IRMA assay on plasma is of minor importance because in the beta cells' secretory pathway these intermediates are negligible. Otherwise, use of an IRMA assay may lead to an overestimated hI quantification when dealing with non-endocrine cells having an hPI cleavage metabolism different from that of beta cells, or when other factors (insulin-like growth factor, degradation products) may interfere. The hPI quantification by ELISA on cell supernatant failed to provide reliable results, probably because of a matrix effect generated by the culture media components or by the reagents employed in the solid-phase extraction. To minimize the source of misreading, a more specific sample pre-treatment (precipitation step) is probably necessary (Kjems et al. 1993).

The first finding of this study with respect to our previous investigation (Falqui et al. 1999) is that although the gene construct inserted into the cells was the same, the hPI conversion pathway appeared different from the primary to the stabilized cell lines, maybe due to the combined action of endogenous endoproteases (Vollenweider et al. 1992) or modified enzyme-tosubstrate ratio. The quali-quantitative pattern of the products released into the medium by transfected cells may vary in relation to the gene constructs and constitutive or co-transfected PC3, PC2, furin (Vollenweider et al. 1992, 1995, Yanagita et al. 1993, Groskreutz et al. 1994, Falqui et al. 1999) or SPC4 (subtilisin-related proprotein convertases) conversion enzymes (Smeekens et al. 1992), and a spontaneous production of hPI derivatives was noted also after subcutaneous administration of hPI in vivo (Peavy et al. 1985).

A very low amount of mature hI was found only in the supernatant of PHM-HPI which comprised also all the intermediate forms and showed the highest production rate on the sum of (pro)insulin related proteins. The 32-33 split and/or des31,32 deriving from furin cleavage of wild-type hPI at the B chain/C-peptide junction (Hutton 1994) were detected in different percentages among the tested cells. Intermediates 65-66 split and/or des64,65, known to have an increase in receptor binding and biological potency in vitro and in vivo as compared with intact hPI (Peavy et al. 1985), were released only by PHM-HPI and HepG2-HPI, maybe by the co-action of another widely expressed enzyme (PACE4) (Hutton 1994). The expression system used here did not fully reproduce the conditions within normal beta cells because of the lack of the specific endoproteases and of the regulated secretory pathway, but the processing conditions occurring in non-endocrine transfected cells could favor the action of furin, which has a neutral $\mathrm{pH}$ optimum instead of the more acid one required for PC2 and PC3 action (Smeekens et al. 1992).

The efficacy of double-mutated hPI gene transduction and of the prohormone processing was confirmed by the high amount of mature hI released into the supernatant by all the transfected cells. In addition to mature hI, all the four intermediates together with the precursor hPI were found in PHM and PHF and the conversion rate to hI (23-29\% respectively) was similar to that of PRH (32\%) but lower than in the other tested cells (46-59\%). In HepG2 cells, hI maturation occurred the most efficient way (59\%), probably related to the highest constitutive furin content (Smeekens et al. 1992, Yanagita et al. 1993), although the unprocessed hPI was still present and the distribution (percentage) of the processing intermediates was different with respect to that found in the primary cells. However, an incomplete post-translational processing of hPI to mature hI was also observed in engineered insulinoma cell lines when proinsulin was expressed at very high levels (Clark et al. 1997).

On the basis of the results obtained we can now better explain the previously demonstrated efficacy of the in vivo transplantation of primary human cells (Falqui et al. 1999). Moreover, we showed that some of the tested cell lines, although unable to quantitatively process hPI to mature hI, released a considerable amount of 65-66 split and/or des64,65, whose activity should be taken into account for a possible therapeutic utilization. These cells seem to be a promising model to develop a regulated insulin-release machinery, being highly expressing lines with efficient maturation of hPI into hI and all the processing intermediates, showing low proliferation and in vitro and in vivo stability of their phenotypic characteristics. Future clinical application of engineered cells requires a regulated release of insulin. Since non-endocrine cells do not possess the mechanisms for regulated (exocitotic) secretion, a conceivable approach is to regulate the level of hormone synthesis by expressing the gene under the transcriptional control 
of glucose-inducible regulatory sequences $(\mathrm{Lu}$ et al. 1998). Alternatively, an inducible release of insulin from engineered cells has been recently obtained by engineering a fusion protein, FKBP12-insulin, that accumulates as aggregates in the endoplasmic reticulum. Rapid release of insulin can be stimulated by a drug that induces protein desegregation (Rivera et al. 2000).

In conclusion, the method proposed proved appropriate for the screening of the metabolic products of human and rodent cells engineered for the non-regulated constitutive released of mature insulin.

\section{Acknowledgements}

This work was supported by a grant from the Ministry of Health (Italy) and by Fondazione Telethon (Italy). The ELISA kits were kindly donated by DAKO (Italy). We thank Dr G Banfi and Dr L Germagnoli (H S Raffaele, Milan, Italy) for ELISA determinations and for their useful discussion. We thank Dr L Monti (H S Raffaele, Milan, Italy) for RIA and IRMA determinations.

\section{References}

Arcelloni C, Falqui L, Martinenghi S, Pontiroli AE \& Paroni R 1998 Capillary electrophoresis for simultaneous quantification of human proinsulin, insulin and intermediate forms. Electrophoresis 19 1475-1477.

Bergmann J, Jaehde U \& Schunack W 1998 Quantitative trace analysis of interleukin-3, interleukin-6, and basic model proteins using isotachophoresis-capillary zone electrophoresis with hydrodynamic counterflow. Electrophoresis 19 305-310.

Chen FTA \& Stenberg JC 1994 Characterization of proteins by capillary electrophoresis in fused-silica columns: review on serum protein analysis and application to immunoassay. Electrophoresis $\mathbf{1 5}$ $13-21$.

Clark SA, Quaade C, Constandy H, Hansen P, Halban P, Ferber S, Newgard CB \& Normington K 1997 Novel insulinoma cell lines produced by iterative engineering of GLUT2, glucokinase, and human insulin expression. Diabetes 46 958-967.

Crowther NJ \& Gray I 1996 Immunometric assays of insulin and its precursors. Journal of Clinical Ligand Assay 19 112-120.

Deberg M, Houssa P, Frank BH, Sodoyez-Goffaux F \& Sodoyez JC 1998 Highly specific radioimmunoassay for human insulin based on immune exclusion of all insulin precursor. Clinical Chemistry $\mathbf{4 4}$ 1504-1513.

Falqui L, Martinenghi S, Severini GM, Corbella P, Taglietti MV, Arcelloni C, Sarugeri E, Monti LD, Paroni R, Dozio N, Pozza G \& Bordignon C 1999 Human fibroblasts genetically engineered to release mature insulin revert hyperglycemia in a murine model of diabetes. Human Gene Therapy 10 1753-1762.

Groskreutz DJ, Sliwkowski MX \& Gorman CM 1994 Genetically engineered proinsulin constitutively processed and secreted as mature, active insulin. Journal of Biological Chemistry 269 6241-6245.

Halban PA 1994 Proinsulin processing in the regulated and constitutive pathway. Diabetologia 37 (Suppl 2) S65-S72.

Houssa P, Dinesen B, Deberg M, Frank BH, Van Schravendijk C, Sodoyez-Goffaux F \& Sodoyez JC 1998 First direct assay for intact human proinsulin. Clinical Chemistry 44 1514-1519.

Hutton JC 1994 Insulin secretory granule biogenesis and the proinsulin-processing endopeptidases. Diabetologia 37 S48-S56.
Kahn SE \& Halban PA 1997 Release of incompletely processed proinsulin is the cause of the disproportionate proinsulinemia of NIDDM. Diabetes 46 1725-1732.

Kaufmann JE, Irminger JC, Mungall L \& Halban PA 1997 Proinsulin conversion in GH3 cells after coexpression of human proinsulin with the endoproteases PC2 and/or PC3. Diabetes 46 978-982.

Kjems LL, Roder ME, Dinesen B, Hartling SG, Jorgensen PN \& Binder C 1993 Highly sensitive immunoassay of proinsulin immunoreactivity with use of two monoclonal antibodies. Clinical Chemistry 39 2146-2150

Kolodka TM, Finegold M, Moss L \& Woo SLC 1995 Gene therapy for diabetes mellitus in rats by hepatic expression of insulin. PNAS 92 3293-3297.

Levine F 1997 Gene therapy for diabetes: strategies for beta cell modification and replacement. Diabetes/Metabolism Research Reviews 13 209-246.

Lu D, Tememoto H, Shibata H, Saito I \& Takeuchi T 1998 Regulatable production of insulin from primary-cultured hepatocytes: insulin production is up-regulated by glucagon and cAMP and down-regulated by insulin. Gene Therapy 5 888-895.

Mavilio F, Ferrari G, Rossini S, NobiliN, Bonini C, Casorati G, Traversari C \& Bordignon C 1994 Peripheral blood lymphocytes as target cells of retroviral vector-mediated gene transfer. Blood $\mathbf{8 3}$ 1988-1997.

Mohamed-Ali V, Nagi DK \& Yudkin JS 1996 Sensitive microplate IRMAs for intact and des31,32-proinsulin compared with HPLC and cellulose IRMAs. Clinical Chemistry 42 977-979.

Mykkanen L, Haffner SM, Hales CN, Ronnemaa T \& Laakso M 1997 The relation of proinsulin, insulin and proinsulin-to-insulin ratio to insulin sensitivity and acute insulin response in normoglycemic subjects. Diabetes 46 1990-1995.

Nagi DK, Hendra YJ, Ryle AJ, Cooper TM, Temple RC, Clark PM, Schneider AE, Hales CN \& Yudkin JS 1990 The relationship of concentrations of insulin, intact proinsulin and 32-33 split proinsulin with cardiovascular risk factors in type 2 (non-insulindependent) diabetic subjects. Diabetologia 33 532-537.

Nashabeh W, Greve KF, Kirby D, Foret F, Karger BL, Relfsnyder DH \& Bullder SR 1994 Incorporation of hydrophobic selectivity in capillary electrophoresis: analysis of recombinant insulin-like growth factor I variants. Analytical Chemistry 66 2148-2154.

Neerrman-Arbez M, Sizonenko SV \& Halban PA 1993 Slow cleavage at the proinsulin B-chain/connecting peptide junction associated with low levels of the endoprotease PC1/3 in transformed beta cells. Journal of Biological Chemistry 268 16098-16100.

Nielsen RG, Sitta Sittampalam G \& Rickard EC 1989 Capillary zone electrophoresis of insulin and growth hormone. Analytical Biochemistry 177 20-26.

Oda RP, Clark R, Katzmann JA \& Landers JP 1997 Capillary electrophoresis as a clinical tool for the analysis of protein in serum and other body fluids. Electrophoresis 18 1715-1723.

Ostrega D, Polonsky K, Nagi D, Yudkin J, Cox LJ, Clark PMS \& Hales CN 1995 Measurements of proinsulin and intermediate. Validation of immunoassay methods by high performance liquid chromatography. Diabetes 44 437-440.

Peavy DE, Brunner MR, Duckworth WC, Hooker CS \& Frank BH 1985 Receptor binding and biological potency of several split forms (conversion intermediates) of human proinsulin. Journal of Biological Chemistry 260 13989-13994.

Rhodes CJ \& Halban PA 1987 Newly synthesized proinsulin/insulin and stored insulin are released from pancreatic beta cells predominantly via a regulated, rather than a constitutive, pathway. Journal of Cell Biology 105 145-153.

Rivera VM, Wang X, Wardwell S, Courage NL, Volchuk A, Keenan T, Holt DA, Gilman M, Orci L, Cerasoli F Jr, Rothman JE \& Clackson T 2000 Regulation of protein secretion through controlled aggregation in the endoplasmic reticulum. Science 287 826-830. 
Sizonenko S, Irminger JC, Buhler L, Deng S, Morel P \& Halban PA 1993 Kinetics of proinsulin conversion in human islets. Diabetes $\mathbf{4 2}$ 933-936.

Smeekens SP, Montag AG, Thomas G, Albiges-Rizo C, Carrol R, Benig M, Phillips LA, Martin S, Ohagi S, Gardner P, Swift HH \& Steiner DF 1992 Proinsulin processing by the subtilisin-related proprotein convertases furin, PC2, and PC3. PNAS 89 8822-8826.

Stocklin R, Vu L, Vadas L, Cerini F, Kippen AD, Offord RE \& Rose K 1997 A stable isotope dilution assay for the in vivo determination of insulin level in humans by mass spectrometry. Diabetes 46 44-50.

Tao L \& Kennedy RT 1997 Measurement of antibody-antigen dissociation constants using fast capillary electrophoresis with laser-induced fluorescence detection. Electrophoresis 18 112-117.

Tao L, Aspinwall CA \& Kennedy RT 1998 On-line competitive immunoassay based on capillary electrophoresis applied to monitoring insulin secretion from single islet of Langerhans. Electrophoresis 19 403-408.

Temple RC, Carrington CA, Luzio SD, Owens DR, Schneider AE, Sobey WJ \& Hales CN 1989 Insulin deficiency in non insulindependent diabetes. Lancet 1 293-295.

Temple RC, Clark PMS, Nagi DK, Schneider AE, Yudkin JS \& Hales CN 1990 Radioimmunoassay may overestimate insulin in non-insulin-dependent diabetics. Clinical Endocrinology 32 698-693.
Vollenweider F, Irminger J-C, Gross DJ, Villa-Komaroff L \& Halban PA 1992 Processing of proinsulin by transduced hepatoma (FAO) cells. Journal of Biological Chemistry 25 14629-14636.

Vollenweider F, Kaufmann J, Irminger JC \& Halban PA 1995 Processing of proinsulin by furin, PC2 and PC3 in (co)transduced COS (monkey kidney) cells. Diabetes 44 1075-1080.

Ward WK, LaCava EC, Paquette TL, Beard JC, Wallum BJ \& Porte D Jr 1987 Disproportionate elevation of immunoreactive proinsulin in type 2 (non-insulin dependent) diabetes mellitus and experimental insulin resistance. Diabetologia 30 698-702.

Yanagita M, Hoshino H, Nakayama K \& Takeuchi Y 1993 Processing of mutated proinsulin with tetrabasic cleavage sites to mature insulin reflects the expression of furin in non-endocrine cell lines. Endocrinology 133 639-643.

Yoshioka N, Kuzuya T, Matsuda A, Taniguchi M \& Iwamoto Y 1988 Serum proinsulin levels at fasting and after oral glucose load in patients with type 2 (non-insulin dependent) diabetes mellitus. Diabetologia 31 355-360.

Received 23 December 1999

Accepted 24 March 2000 